
D:INsurg|Vol. 24, No. 1, Jan. - Mar., 2020\Nsurg-4.Doc
(A)
P. $33-38$
II

ORIGINAL ARTICLE

\title{
Comparison of Frequency of Recurrence after Burr Hole Evacuation of Chronic Subdural Hematoma with or without Subdural Drain
}

\author{
MUHAMMAD ABDUR REHMAN ${ }^{1}$, TALHA ABBAS ${ }^{2}$, NABEEL CHOUDHARY \\ TAIMOOR ANWAR ${ }^{1}$, ANUM WAHAB ${ }^{1}$, QURA TUL AIN TARIQ ${ }^{\mathbf{1}}$ \\ ${ }^{1}$ Department of Neurosurgery, Allied Hospital, ${ }^{2}$ Independent Medical College, Faisalabad \\ ${ }^{3}$ Allama Iqbal Medical College, Lahore - Pakistan
}

DOI: $10.36552 /$ pjns.v24i1.380

\begin{abstract}
Objectives: Chronic subdural hematoma (CSDH) after surgical treatment shows the recurrence rate of approximately 5 to $30 \%$. We compared the frequency of recurrence after BE of CSDH with and without subdural drain.

Materials and Methods: The study was a randomized controlled trial carried out in The Department of Neurosurgery, Allied Hospital, Faisalabad. Patients with an emergency mode of admission satisfying the inclusion criteria and giving the informed consent were enrolled for study. Patients in first "A group" underwent BE (burr hole evacuation) with a drain and patients in "group B" were treated without placement of the drain.

Results: The total number was 130 out of which 65 were placed in each group. $84.62 \%$ of A Group and $76.92 \%$ of B Group were above 40 years, whereas $15.38 \%$ in A Group and $23.08 \%$ were above $18-40$ years. The mean \& $\pm S D$ was calculated as $64.03 \pm 7.61$ years in A Group and $62.28 \pm 7.83$ years in B Group, $78.46 \%$ in A Group and $72.31 \%$ in B Group were of male gender while $21.54 \%$ in A Group and $27.69 \%$ in B Group were of females gender. The comparison between frequency of recurrence after BE of CSDH with and without subdural drain shows $10.77 \%$ in A Group and 27.69\% in the B Group, $p$ value was 0.01 showing a significant difference.
\end{abstract}

Conclusion: The frequency of recurrence after burr hole evacuation of CSDH is significantly lower when a subdural drain is placed as when compared to without subdural drain.

Keywords: Burr hole evacuation, Chronic subdural hematoma, subdural drain.

\section{INTRODUCTION}

The objective of this study was to compare the frequency of recurrence after $\mathrm{BE}$ of $\mathrm{CSDH}$ with and without subdural drain. The chronic subdural hematoma is not a very uncommon neurosurgical disease. In literature, the incidence is roughly 3/100,000 and increases considerably in the elderly population. ${ }^{1}$ Risk factors include head injury and even trivial head trauma in advanced-age, frequent falls, and coagulopathies, including use of anticoagulants. It can also be iatrogenic due to cerebrospinal fluid (CSF) shunts and over shunting conditions. Brain atrophy due to advance age results in an increase of subdural space which in turn facilitates CSDH formation. Subdural hematoma may also occur in younger patients and is supposed to be due to intracranial hypotension secondary to spontaneous CSF leaks, vascular diseases like aneurysms, arteriovenous malformations (AVM), infections, coagulopathies, dural sinus thrombosis neoplasms, and cocaine or alcohol abuse. $^{2}$ 
The symptomatic CSDH is treated by surgical evacuation, which usually results in "quick fix" improvement of the neurological status. ${ }^{3}$ An arsenal of surgical procedures are available. Among these are twist drill craniostomy, burr hole evacuation, limited craniotomy or widened burr hole, craniotomy, endoscope assisted evacuation, and sometimes subduro-peritoneal shunt. However, each of these procedures has its own burden of complications. ${ }^{4}$

Burr-hole evacuation through a single burr hole or two burr-holes is worldwide accepted surgical technique. ${ }^{5}$ Different authors have suggested BE or limited craniectomies. Placement of subdural drain combined with single BE use of drains and irrigation of the subdural space. ${ }^{6}$

Recurrence of $\mathrm{CSDH}$, if occurs, is a major problem in terms of morbidity and mortality. These patients not only require redo evacuations, but sometimes also become resistant to redo evacuation and at times a big flap craniotomy are required to peel off thick membrane over cortex which may result in epilepsy. In literature, there is huge data available regarding CSDH management, but it is confusing to infer which modality is superior to another. Likewise, a placement of drain in the $\mathrm{BE}$ is also controversial as in one study recurrence rate after $\mathrm{BE}$ with drain was only $9 \%$ while without drain it was as high as $26 \%{ }^{7}$ Another study failed to show any difference burr hole evacuation with or without drainage having an equal recurrence rate $(5 \%) .{ }^{8}$ In our routine practice, only $\mathrm{BE}$ without drainage was performed as a first line of treatment for CSDH. No consensus exists on usage of subdural drain among different neurosurgeons. My study results may ease the decision making in selecting the placement of subdural drain as a standard treatment for $\mathrm{CSDH}$ in minimizing recurrence.

\section{MATERIALS \& METHODS}

The study was a randomized controlled trial carried out in The Department of Neurosurgery, Allied Hospital Faisalabad, in two years duration between Aug. 2016 to July 2018.

\section{Sample Size and Study Design}

With the help of a sample size calculator recommended by WHO for 2 groups, $\mathrm{P}_{1}=9 \%{ }^{7} \& \mathrm{P}_{2}=$ $26 \%{ }^{7}$ respectively. The power of study was $80 \%$, with significance level $=5 \%$ the Sample size of $n=65$ was placed in each group. The sample size $\mathrm{N}=130$ was the total. Non probability sampling technique was employed.

\section{Inclusion Criteria}

Patients of both genders, male and female of age grater then 18 - years. Patients having symptomatic CSDH.

\section{Exclusion Criteria}

Pediatric population. Patients with cerebrospinal fluid (CSF) diversion procedures. Patients who required surgery other than burr-hole evacuation will burr hole evacuation. Clinically non symptomatic hematoma patients.

\section{Data Collection Procedure}

After hospital ethical committee approval, patients with an emergency mode of admission satisfying the inclusion criteria and giving the informed consent were enrolled for study. Two equal population groups (65 each) were randomly allotted to the patients by number generated by computer. Patients in first " $A$ group" underwent $\mathrm{BE}$ with a drain and patients in "group B" were treated without placement of drain. Both procedures were performed under general anesthesia. Recurrence was assessed after 3 months of treatment as per operational definition. CT scan was performed and reported by radiology department of the same hospital and it was reported by the consultant radiologist. A specially designed proforma was used for data collection.

\section{DATA ANALYSIS}

For data collection and analysis, SPSS version 20 was applied. The qualitative variables like gender and recurrence frequency along with percentage were calculated. Chi-square test was applied to compare the recurrence burr hole groups. Descriptive statistics including mean and standard deviation of numerical values like age and duration of disease were evaluated. Effect modifiers like age, gender and duration of disease was controlled by stratification. Chi-square test was applied after stratification. P-value $\leq 0.05$ was considered significant.

\section{RESULTS}

Patients who fulfilled the inclusion criteria were 130 . Half of the patients, i.e., $\mathrm{n}=65$ placed in group $\mathrm{A}$ underwent $\mathrm{BE}$ with drain and the other half $\mathrm{n}=65$ 
patients in group $B$ who underwent BE without drainage.

\section{Age Incidence}

As far as the age distribution of the patients is concerned, the patients above 40 years of age were $84.62 \%(\mathrm{n}=55)$ in A Group and $76.92 \%(\mathrm{n}=50)$ in B Group whereas patients from 18 to 40 were $15.38 \%$ $(\mathrm{n}=10)$ in A Group and $23.08 \%(\mathrm{n}=15)$ were in $\mathrm{B}$ Group $18-40$ years Mean \pm SD was calculated as $64.03 \pm 7.61$ years in A Group and 65.28 \pm 7.83 years in B Group as showed in Table 1.

Table 1: Distribution According To Age $(N=130)$.

\begin{tabular}{|c|c|c|c|c|}
\hline \multirow{2}{*}{$\begin{array}{c}\text { Age } \\
\text { (in Years) }\end{array}$} & \multicolumn{2}{|c|}{ A Group $(n=65)$} & \multicolumn{2}{|c|}{ A Group $(n=65)$} \\
\hline & $\begin{array}{l}\text { Patients } \\
\text { Number }\end{array}$ & $\%$ & $\begin{array}{l}\text { Patients } \\
\text { Number }\end{array}$ & $\%$ \\
\hline $18-40$ & 10 & 15.38 & 15 & 23.08 \\
\hline$>40$ & 55 & 84.62 & 50 & 76.92 \\
\hline Total & 65 & 100 & 65 & 100 \\
\hline Mean \& SD & \multicolumn{2}{|c|}{$64.03 \pm 7.61$} & \multicolumn{2}{|c|}{$62.28 \pm 7.83$} \\
\hline
\end{tabular}

\section{Gender Distribution}

Distribution according to gender showed that $78.46 \%$ $(\mathrm{n}=51)$ in A Group and $72.31 \%(\mathrm{n}=47)$ in B Group were men while $21.54 \%(\mathrm{n}=14)$ in A Group and $27.69 \%(\mathrm{n}=18)$ in B Group were women (Table 2).

Table 2: Shows Distribution According to Gender $(N=$ 130).

\begin{tabular}{||l||c|c||c||c||}
\hline \multirow{2}{*}{ Gender } & \multicolumn{2}{|c|}{ A Group $(\mathbf{n}=\mathbf{6 5})$} & \multicolumn{2}{c||}{ B Group $(\mathbf{n}=\mathbf{6 5})$} \\
\cline { 2 - 5 } & $\begin{array}{c}\text { Patient's } \\
\text { Number }\end{array}$ & $\%$ & $\begin{array}{c}\text { Patient's } \\
\text { Number }\end{array}$ & $\%$ \\
\hline \hline Men & 51 & 78.46 & 47 & 72.31 \\
\hline \hline Women & 14 & 21.54 & 18 & 27.69 \\
\hline \hline Total & $\mathbf{6 5}$ & $\mathbf{1 0 0}$ & $\mathbf{6 5}$ & $\mathbf{1 0 0}$ \\
\hline
\end{tabular}

\section{Recurrence}

Comparison of frequency of recurrence after $\mathrm{BE}$ $10.77 \%(\mathrm{n}=7)$ in A Group and $27.69 \%(\mathrm{n}=18)$ in Group B while $89.23 \%(\mathrm{n}=58)$ in A Group and $72.31 \%(\mathrm{n}=47)$ in $\mathrm{B}$ Group had no findings of recurrence, $\mathrm{p}$ value was 0.01 showing a significant difference (Table 3 ).

Table 3: The Comparison of Frequency of Recurrence after Surgery of $\mathrm{CSDH}$ with and Without Placement of Subdural Drain $(N=130)$.

\begin{tabular}{|c|c|c|c|c|}
\hline \multirow{2}{*}{ Recurrence } & \multicolumn{2}{|c|}{$\operatorname{Group} A^{*} \quad(n=65)$} & \multicolumn{2}{|c|}{ Group B* $\quad(n=65)$} \\
\hline & Number & $\%$ & Number & $\%$ \\
\hline Present & 7 & 10.77 & 18 & 27.69 \\
\hline Absent & 58 & 89.23 & 47 & 72.31 \\
\hline Total & 65 & 100 & 65 & 100 \\
\hline
\end{tabular}

Group A* = With Drain

$P$ value $=0.01$

Table 4: Patient's Stratification for Recurrence According to Age $(N=130)$.

AGE: 18 - 40 Years

\begin{tabular}{|c|c|c|c|}
\hline \multirow{2}{*}{ Group } & \multicolumn{2}{|c|}{ Recurrence } & $P$ value \\
\hline & Yes & No & \multirow{3}{*}{0.13} \\
\hline A & 0 & 10 & \\
\hline B & 3 & 12 & \\
\hline
\end{tabular}

AGE: > 40 Years

\begin{tabular}{|c|c|c|c|}
\hline \multirow{2}{*}{ Group } & \multicolumn{2}{|c|}{ Recurrence } & $P$ value \\
\hline & Yes & No & \multirow{3}{*}{0.02} \\
\hline A & 7 & 48 & \\
\hline B & 15 & 35 & \\
\hline
\end{tabular}

Table 5: Patient's Stratification for Recurrence According to Gender $(N=130)$.

MALE $(\mathbf{N}=\mathbf{9 8})$

\begin{tabular}{|c|c|c|c|}
\hline \multirow{2}{*}{ Group } & \multicolumn{2}{|c|}{ Recurrence } & $P$ value \\
\hline & Yes & No & \multirow{3}{*}{0.04} \\
\hline A & 5 & 46 & \\
\hline B & 12 & 35 & \\
\hline
\end{tabular}

FEMALE $(\mathbf{N}=\mathbf{3 2})$

\begin{tabular}{|c|c|c|c|}
\hline \multirow{2}{*}{ Group } & \multicolumn{2}{|c|}{ Recurrence } & $P$ value \\
\hline & Yes & No & \multirow{3}{*}{0.31} \\
\hline $\mathrm{A}$ & 2 & 10 & \\
\hline B & 8 & 12 & \\
\hline
\end{tabular}


Table 6: Patient's Stratification for Recurrence According to Disease Duration $(N=130)$

1- 2 Months

\begin{tabular}{|c|c|c|c|}
\hline \multirow{2}{*}{ Group } & \multicolumn{2}{|c|}{ Recurrence } & $P$ value \\
\hline & Yes & No & \multirow{3}{*}{0.01} \\
\hline A & 6 & 53 & \\
\hline B & 15 & 40 & \\
\hline
\end{tabular}

$>2$ Months

\begin{tabular}{||c||c|c||c|}
\hline \multirow{2}{*}{ Group } & \multicolumn{2}{c||}{ Recurrence } & \multirow{2}{*}{ P value } \\
\cline { 2 - 3 } & Yes & No & \multirow{2}{*}{0.55} \\
\hline \hline A & 1 & 5 & \\
\hline \hline B & 3 & 7 & \\
\hline
\end{tabular}

The data for effect modifiers like age, gender and duration of disease was stratified and controlled. After stratification chi-square test was applied. A P-value $\leq 0.05$ was considered significant (Tables. $4-6$ ).

\section{DISCUSSION}

The Chronic subdural hematoma is notorious to recur and the recurrence rates range from around $8 \%$ to $39 \%$. In routine practice Burr Hole Evacuation (BE) without drainage was performed as the most popular way of surgical treatment for subdural hematoma. In our study, the placement of drainage after the burr hole evacuation has shown to decrease recurrence significantly.

Our study showed $84.62 \%(\mathrm{n}=55)$ in A Group and $76.92 \%(\mathrm{n}=50)$ in B Group, were above 40 years of age, which is according to natural history of this disease, whereas, $15.38 \%(\mathrm{n}=10)$ in A Group and $23.08 \%(\mathrm{n}=15)$ were between $18-40$ years of age. Mean \pm SD came out to be $64.03 \pm 7.61$ years in A Group and $62.28 \pm 7.83$ years in B Group, which is also according to well-known course of this ailment. A male preponderance was observed in our study as $78.46 \%(\mathrm{n}=51)$ in A Group and $72.31 \%(\mathrm{n}=47)$ in B Group were male, while 21.54\% $(\mathrm{n}=14)$ in A Group and $27.69 \%(\mathrm{n}=18)$ in B Group were females. Comparison of frequency of recurrence after BE of $\mathrm{CSDH}$ with and without subdural drain showed $10.77 \%(\mathrm{n}=7)$ in A Group and $27.69 \%(\mathrm{n}=18)$ in B Group. The p-value was 0.01 which means a statistically significant difference in recurrence and favors the placement of drain over no drain.
In comparison of our study results with one of the previous studies showing recurrence after BURR HOLE drainage with drain in $9 \%$ and without drain it was recorded as $26 \% .^{7}$ In another study, BE with drainage and without it showed an equal recurrence rate $(5 \%){ }^{8}$ These findings do not correspond to our result.

The use of external drainage after evacuation of $\mathrm{CSDH}$ is supported by a considerable reported series. ${ }^{9,10}$ Santarius et al., ${ }^{9}$ Ramachandran et al,. ${ }^{11}$ Wakai et al., ${ }^{12}$ Tsutsumi et al., ${ }^{13}$ and Gurelik et al. ${ }^{14}$ and Sarnvivad et $\mathrm{al}^{15}$ reported $9.3 \%, 4 \%, 5 \%, 3.1 \%$, $10.5 \%$, and $16 \%$ recurrence rates, respectively, in the drainage group, as compared to $24 \%, 30 \%, 33 \%, 17 \%$, $19 \%$, and $26 \%$, respectively, in without drain group. Continuously placing a subdural drain for CSDH for short period of time appears to be superior to the single time drainage techniques, in terms of shorter post-op hospitalization and low recurrence.

Some studies in the literature were unable to show a significant difference in the postoperative reaccumulation of CSDH and the rates of other complication in drain age group and without drainage groups which is contrary to our study. ${ }^{16,17}$ Studies in favor of no drain argue that putting a drain could lead to complications such as hemorrhage, brain injury and infection without significantly altering the recurrence rate. Infective complications such as subdural empyemas have been reported after subdural drain. ${ }^{17}$ Postoperative infection in the subgaleal space has also been reported after drainage, but being the limitation of this study, we did not record it which may be done in coming trials.

This study with the support of other studies mentioned above justify the judgment that "burr hole evacuation of CSDH with drain is better than without drain in terms of recurrence". The main limitation of this study is that it is a single centre study. However, our findings may be validated through some other local multicenter trials.

\section{CONCLUSION}

We concluded that the frequency of recurrence after burr hole evacuation of CSDH is significantly lower with drain when compared without subdural drain. The results of the current study may be helpful in settling down controversies of selecting a proper treatment modality as a standard treatment for CSDH in terms of recurrence. 


\section{REFERENCES}

1. Regan JM, Worley E, Shelburne C, Rullerkat R, Watson JC. BURR HOLE washout versus craniotomy for chronic subdural hematoma: patient outcome and cost analysis. PLoS One. 2015; 10: eo115085.

2. Rusconi A, Sangiorgi S, Bifone L, Balbi S. Infrequent hemorrhagic complications following surgical drainage of chronic subdural hematoma. J Korean Neurosurg Soc. 2015; 57: 379-85.

3. Rovlias A, Theodorpoulos S, Papoutsakis D. Chronic subdural hematoma: surgical management and outcome in 986 cases: a classification and regression tree approach. Surg Neurol lnt. 2015; 6: 127.

4. Kim GH. Kim BT, lm SB, Hwang SC, Jeong JH. Shin DS. Comparison of the indications and treatment results of burr-hole drainage at the maximal thickness area versus twist-drill craniostomy at the pre-coronal point for the evacuation of symptomatic chronic subdural hematoma. J Korean Neurosurg Soc. 2014; 56: 243-7.

5. Balser D, Rodgers SD, Johnson B, Shi C, Tabak E, Samadani U. Evolving management of symptomatic chronic subdural hematoma: experience of a single institution and review of the literature. Neurol Res. 2013; 35: 233-42.

6. Kutty SA, Johny M. Chronic subdural hematoma: a comparison of recurrence rates following burr-hole craniostomy with and without drains. Turk Neurosurg. 2014; 24: 494-7.

7. Singh AK, Suryanarayanan B', Choudhary A, Prasad A, Singh S, Gupta LN. A prospective randomized study of use of drain versus no drain after burr-hole evacuation of chronic subdural hematoma. Neurol India, 2014; 62: 169-74.

8. Javadi A. Amirjamshidi A, Aran S, Hosseini SH. A randomized controlled trial comparing the outcome of burr-hole irrigation with and without drainage in the treatment of chronic subdural hematoma: a preliminary report. World Neurosurg. 2011; 75: 731-6.
9. Santarius T, Kirkpatrick PJ, Ganesan D, Chia HL, Jalloh I, Smielewski P. Use of drains versus no drains after burr-hole evacuation of chronic subdural haematoma: A randomised controlled trial. Lancet, 2009; 374: 1067-73.

10. Carlsen JG, Cortnum S, Sørensen JC. Recurrence of chronic subdural haematomata with and without postoperative drainage. Br J Neurosurg. 2011; 25: 388-90.

11. Ramachandran R, Hegde T. Chronic subdural hematomas: Causes of morbidity and mortality. Surg Neurol. 2007; 67: 367-72.

12. Wakai S, Hashimoto K, Watanaburrhole N, Inoh S, Ochiai C, Nagai M. Efficacy of closed-system drainage in treating chronic subdural hematoma: A prospective comparative study. Neurosurgery, 1990; 26: 771-3.

13. Tsutsumi K, Maeda K, Iijima A, Usui M, Okada Y, Kirino T. The relationship of preoperative magnetic resonance imaging findings and closed system drainage in the recurrence of chronic subdural hematoma. J Neurosurg. 1997; 87: 870-5.

14. Gurelik M, Aslan A, Gurelik B, Ozum U, Karadag O, Kars HZ. A safe and effective method for treatment of chronic subdural haematoma. Can J Neurol Sci. 2007; 34: 84-7.

15. Sarnvivad P, Chiewchanvechakul W, Chumnanvej S. Chronic subdural hematoma: Drainage vs. no drainage. J Med Assoc Thai. 2011; 94: 1352-6.

16. Javadi A, Amirjamshidi A, Aran S, Hosseini SH. A randomized controlled trial comparing the outcome of burr-hole irrigation with and without drainage in the treatment of chronic subdural hematoma: A preliminary report. World Neurosurg. 2011; 75: 731-6.

17. Ahmed S, Agrawal D, Kale SS, Mahapatra AK. A comparative study of treatment of chronic subdural hematoma: BURR HOLE drainage versus continuous closed drainage. The Indian Journal of Neurotrauma. 2011; 8: 17-24.

\section{Additional Information}

Disclosures: Authors report no conflict of interest.

Ethical Review Board Approval: The study was conformed to the ethical review board requirements.

Human Subjects: Consent was obtained by all patients/participants in this study.

Conflicts of Interest:

In compliance with the ICMJE uniform disclosure form, all authors declare the following:

Financial Relationships: All authors have declared that they have no financial relationships at present or within the previous three years with any organizations that might have an interest in the submitted work.

Other Relationships: All authors have declared that there are no other relationships or activities that could appear to have influenced the submitted work. 
Address for Correspondence:

Dr. Talha Abbas

Independent University Hospital

Marzi Pura Narr Wala Road, Faisalabad

Cell: +923004270295

Email:drtalhamalik@gmail.com

\begin{tabular}{|c|c|c|c|}
\hline \multicolumn{4}{|c|}{ AUTHORSHIP AND CONTRIBUTION DECLARATION } \\
\hline Sr.\# & Author's Full Name & Intellectual/Contribution to Paper in Terms of: & Signature by the \\
\hline 1. & Muhammad Abd-ur-Rehman & 1. Main investigator/ data collection. & a \\
\hline 2. & Talha Abbas & 2. Data analysis and report writing & ard \\
\hline 3. & Nabeel Choudhary & 3. Data analysis and report writing & 2estas \\
\hline 4. & Taimoor Anwar & 4. Co investigator and data collector. & \\
\hline 5. & Anum Wahab & 5. Literature review and Manuscript writing & \\
\hline 6. & Qurat-ul-Ain Tariq & 6. Analysis of data and quality insurance & \\
\hline
\end{tabular}

Date of Submission: 20-1-2020

Date of Revision: 12-03-2020

Date of Online Publishing: 31-03-2020

Date of Print: 31-03-2020 